\title{
Desenvolvimento, meio ambiente e produção do espaço: análise de indicadores socioeconômicos e ambientais na Bacia do Itajaí (SC)
}

Rogério Goulart Junior*

\begin{abstract}
Resumo
O processo de crescimento econômico pode ser questionado a partir do problema ambiental e dos conceitos de desenvolvimento sustentável e sustentabilidade da economia neoclássica, em relação à economia ecológica. Mas é preciso compreender os conflitos entre o capital e o trabalho no tocante à apropriação dos recursos e da riqueza natural, e o impacto ambiental da acumulação capitalista gerada pelas frações de capital na urbanização resultante da divisão do trabalho no espaço urbano brasileiro. Na produção espacial são estudados alguns aspectos da formação socioespacial e territorial a partir do recorte da bacia hidrográfica, focalizando a bacia do Itajaí, em Santa Catarina. Assim, foram realizadas análises estatísticas descritivas de municípios e usuários de água, e, ainda, foram analisados indicadores socioeconômicos e ambientais municipais por meio de análise de correlação e análise multivariada de clusters e componentes principais. Na análise dos componentes principais verificou-se que os menores valores para o índice de gestão de recursos hídricos ocorreram em municípios com predomínio de atividades pecuárias, o que pode indicar a necessidade de um melhor controle e participação municipal em ações relacionadas aos recursos hídricos locais.

Palavras-chave: desenvolvimento e meio ambiente; indicadores socioeconômicos ambientais, bacia hidrográfica do Itajaí (SC)

\section{Development, environment and production of space:}

\section{analysis of socioeconomic and environmental indicators concerning the Itajaí Basin (SC)}

\begin{abstract}
The process of economic growth can be questioned from the point of view of the environmental problem and the concepts of sustainable development and sustainability of the neoclassical economy, in relation to the ecological economy. But it is necessary to understand the conflicts between capital and labor concerning the appropriation of resources and natural wealth, and the environmental impact of the capitalist accumulation generated by the fractions of capital in the urbanization resulting from the division of labor in the Brazilian urban space. In space production some aspects of the sociospatial and territorial formation are studied, taking as unit of analysis the hydrographic basin of the Itajaí River, in Santa Catarina. Thus, descriptive statistical analyzes about the municipalities and also water users were carried out, and municipal socioeconomic and environmental indicators were looked upon through correlation analysis and multivariate analysis of clusters and of main components. Analysis of main components allowed the verification that the lowest values for the index of water resources management occurred in municipalities with predominance of livestock activities, which may indicate the need for a better control and for municipal participation in initiatives related to local water resources.
\end{abstract}

Keywords: development and environment; environmental socioeconomic indicators; Itajaí hydrographic basin

\footnotetext{
${ }^{*}$ Epagri/Cepa. E-mail: rogerio.econ@ibest.com.br
} 
JEL Classification: C38, O13, Q25, Q56, Q57, R11

\section{Introdução}

$\mathrm{Na}$ discussão sobre o desenvolvimento econômico e o meio ambiente, uma das questões fundamentais é a compreensão dos limites da expansão econômica perante o ecossistema, e, a partir disso, o questionamento dos conceitos de sustentabilidade e de crescimento econômico e os padrões ilimitados de produção e consumo no capitalismo.

As possibilidades de mudanças socioeconômicas, culturais e institucionais, ao considerar a problemática de diferentes escalas (econômica e ecológica), justiça distributiva e alocação dos recursos em regiões e países com grau de desenvolvimento distinto, são primordiais para a definição de políticas de desenvolvimento social, econômico e ecológico.

Mas o espaço é uma construção social em todas as suas dimensões e as mudanças socioespaciais são reguladas pela lógica da acumulação de capital, que, na sociedade capitalista, tem como resultado desse processo o desenvolvimento desigual. Assim, para Gottdiener (2010), a transformação da sociedade deve ser feita através de uma criação consciente de novas relações socioespaciais.

A cada momento o processo social envolve uma redistribuição dos seus fatores. E essa redistribuição não é indiferente às condições preexistentes, isto é, às formas herdadas, provenientes de momentos anteriores. Conforme Santos (2009a), as formas naturais e o meio ambiente construído incluem-se entre essas formas herdadas.

Neste contexto, a utilização de indicadores socioeconômicos e ambientais pode contribuir para a compreensão das inter-relações existentes entre os diversos grupos sociais envolvidos nas decisões sobre o meio ambiente e as características ecológicas e econômicas do espaço em questão.

\section{Crescimento econômico, desigualdade e meio ambiente}

Para Veiga (2005), há três tipos de questionamentos sobre o desenvolvimento: um que seria sinônimo de crescimento econômico, e a evolução de indicadores relacionados à produção seria uma das maneiras de mensuração do desenvolvimento; outro que compreende o desenvolvimento como mito ou ilusão; e o último que recusa os dois tipos anteriores, que tenta explicar o desenvolvimento como crescimento e distribuição de renda.

Na visão do sinônimo entre os termos, até os anos 1960 a industrialização era tida como a força motriz determinante para as poucas nações desenvolvidas serem também ricas 
em termos de produção nacional; e assim, o sinônimo dos conceitos ser válido. Mas o intenso crescimento econômico em países "semi-industrializados" não determinou necessariamente uma maior participação da população de baixa renda no acesso a bens materiais, saúde e educação, entre outros.

Com isso, surgiram discussões sobre a possibilidade do conceito de desenvolvimento ser expandido para além do simples aumento na renda per capita ou renda por trabalhador. Mesmo com estas evidências muitos manuais sobre ciência econômica convencional trazem os dois termos como sinônimos.

Veiga (2005) destaca que o desenvolvimento como ilusão ou mito tenta demonstrar a impossibilidade de mudanças substantivas na hierarquia de nações tipificadas pelo PNB per capita.

Para este autor, a metodologia adotada pelo economista e sociólogo Giovanni Arrighi estabeleceria apenas uma simples equivalência entre desenvolvimento e riqueza, reforçando a ideia comum da economia convencional do sinônimo entre os conceitos. Como também, argumenta que, para Arrighi (1997) a riqueza não pode ser buscada "como um fim em si mesmo", mas como um meio para obter outras coisas, que inclua as noções de bem-estar, poder ou uma combinação disso e, por isso, o desenvolvimento seria uma ilusão.

O "caminho do meio", para Veiga (2005), seria o proposto por Amartya Sen sobre o papel das diferentes formas de liberdade no combate às ditas privações absurdas, destituições e opressões existentes num mundo com muita riqueza. Ele destaca que o século XX, com regimes democráticos e participativos, convive com problemas antigos como a pobreza e necessidades não satisfeitas, fomes coletivas e crônicas; violação de liberdades políticas e formais tanto em países pobres como em países ricos.

Assim, Veiga concorda com Sen (1999), que o combate destes problemas se daria pela garantia de liberdade individual como comprometimento social, sendo, assim, o fim e o meio para o desenvolvimento. Para ambos o crescimento econômico pode ser muito importante como meio de expandir as liberdades e, então, a industrialização, o progresso tecnológico ou a modernização social podem contribuir para a expansão da liberdade humana.

$\mathrm{E}$, com isso, o desenvolvimento depende de liberdades substantivas individuais e garantias das liberdades políticas, sociais e econômicas, por meio da combinação de crescimento com distribuição de renda e acesso ao mercado. No entanto, reflete Veiga, é de Celso Furtado a melhor fórmula sintética sobre a definição de desenvolvimento, em que o crescimento econômico seria a preservação de privilégios das elites; e o desenvolvimento é 
caracterizado pelo projeto social que prioriza a efetiva melhoria das condições de vida da população em questão.

Segundo Abramovitz (1989), com as discussões sobre desenvolvimento, o crescimento econômico na literatura técnica passou a significar apenas uma capacidade maior de produzir e, portanto, uma maior variedade de escolha entre os bens, entre bens e lazer, e na distribuição dos bens entre as pessoas.

Mas o julgamento prático dos economistas neoclássicos não mudou. Tal como acontece com as pessoas em geral, este grupo continuou a apoiar a visão de que o crescimento econômico conduz ao bem-estar. Em geral, eles ainda o fazem, e com base nesta posição é tomada uma série de decisões concretas. São esses julgamentos que são cada vez mais a causa da necessidade de revisão dos conceitos sobre desenvolvimento.

Para Abramovitz, na reavaliação do crescimento econômico, se partir do produto nacional líquido como sua medida convencional, a primeira crítica geral a ser sustentada será que a medida é um guia enganador para o crescimento do bem-estar econômico.

Esta medida pode ser mais bem conhecida, mas não necessariamente a mais importante, pois ignora os custos externos da produção e do consumo. Estes custos são as perdas de recursos valiosos e escassos; por isso podem ser usados como mercadoria isenta de produtores e consumidores, e deixar de serem subtraídos do total do produto líquido. Se estes custos estão subindo, a taxa de crescimento real líquido é menor do que a medida convencional.

Os exemplos incontáveis de tais custos externos são a poluição da água e do ar por atividades de indústrias, automóveis, pelo aquecimento doméstico, esgoto, congestionamento nas estradas, danos a áreas selvagens e do despovoamento ou a extinção de certas espécies de animais selvagens, entre outros.

Altvater (1996) se alinha à opinião de que o desenvolvimento é contrário ao meio ambiente, argumentando que o desenvolvimento se realiza no espaço global, mas de modo extremamente descontínuo e não simultâneo nas diversas nações e regiões do mundo.

Para Altvater, quem pretende se ocupar hoje da dinâmica de desenvolvimento econômico no futuro precisa levar em conta as condições iniciais e de contexto para o crescimento e o desenvolvimento produzidas no passado, e que são atualmente dominantes. Assim, o desenvolvimento não ocorre num laboratório atemporal e independente de sua localização, mas num espaço natural e social, e em épocas históricas.

O modelo da industrialização capitalista não é universalizável, pois não parece ser possível espalhar pelo mundo inteiro um modo de vida e de trabalho, que se baseia em um 
elevado consumo energético e material; que precisa dispor de sistemas energéticos e de transformação materiais eficientes e inteligentes; e que precisa realizar e organizar nesta base uma prática de vida europeia-ocidental, com os correspondentes modelos ideológicos e de pensamento e instituições políticas e sociais reguladoras (ALTVATER, 1996).

Assim, construir de um modo novo e eficaz as instituições de regulação apropriadas ao sistema industrial num país pressupõe o respeito a interferências globais, pois um sistema industrial nacional torna-se economicamente parte do mercado mundial.

As sociedades industriais só podem reivindicar para si as benesses da afluência industrial enquanto o mundo ainda hoje não industrializado assim permanecer. Se os recursos naturais da Terra fossem ilimitados, se a capacidade das áreas do planeta para receber as emissões poluentes da industrialização não fosse finita, esse problema não existiria. Nestes termos, necessitam-se recursos naturais (energias e matérias-primas e também cada vez mais das fontes genéticas localizadas, sobretudo no Sul) e precisa-se de "recipientes" (locais de despejo onde os rejeitos gasosos, líquidos e sólidos possam ser absorvidos ou depositados).

Mas, segundo Altvater (1996), uma sociedade industrial capitalista é expansiva no tempo e no espaço, ampliando-se aceleradamente. Mesmo com crescimento zero, visto por uma série de ecologistas como uma solução para os problemas ambientais, gastam-se energia e matérias-primas, ainda que o crescimento em valor econômico/monetário seja zero ou negativo. Poderá até mesmo ocorrer que, com crescimento zero, o ônus ambiental seja maior do que com crescimento positivo, devido à obrigação de poupar custos no sistema econômico.

Portanto, o problema não reside na dimensão dos coeficientes de crescimento econômico, mas no modo de regulação do "metabolismo", da troca material entre natureza, indivíduo e sociedade. A transferência de tecnologia dos países industrializados aos países menos industrializados é uma necessidade, que não se efetiva por restrições sistêmicas.

Veiga (2005) discute visões de diferentes autores, com três tipos de respostas que são apresentadas e examinadas.

Em primeiro, os que simplesmente acreditam que não existe dilema entre conservação ambiental e crescimento econômico, ou seja, que seja factível combinar essa dupla exigência. Mas, não há qualquer evidência científica sobre as condições em que poderia ocorrer tal conciliação.

Conforme Veiga (2005), na segunda visão, as pesquisas de Nicholas GeorgescuRoegen lançaram o alerta sobre o inexorável aumento da entropia baseado na segunda lei da termodinâmica; ele assinalou que as atividades econômicas gradualmente transformam 
energia em formas de calor tão difusas que são inutilizáveis. Pois, quando utilizada, uma parte da energia de baixa-entropia (livre) se torna de alta entropia (presa).

Assim, para poder manter seu próprio equilíbrio, a humanidade tira da natureza os elementos de baixa entropia que permitem compensar a alta entropia que ela usa.

Com isso, o crescimento econômico exigiu a extração da baixa entropia contida no carvão e no petróleo. Para Georgescu-Roegen, em algum momento do futuro, a humanidade deverá apoiar a continuidade de seu desenvolvimento na retração, isto é, com o decréscimo do produto.

Para a corrente mais cética desta visão, representada por Herman Daly, só haverá alternativa à decadência ecológica na chamada "condição estacionária", que não corresponde a crescimento zero. Ou seja, na condição estacionária, a economia continuaria a melhorar em termos qualitativos, substituindo, por exemplo, energia fóssil por energia limpa.

A terceira originou-se com as discussões sobre a noção de sustentabilidade a partir do relatório "Nosso Futuro Comum" ou "Relatório Brundtland", que caracterizou o desenvolvimento sustentável como um conceito político e um conceito amplo para o progresso econômico e social. Nesta corrente se destaca Robert Solow; na sua teoria a natureza jamais constituirá sério obstáculo à expansão, pois, no longo prazo, os ecossistemas não oferecerão qualquer tipo de limite, seja como fontes de insumos ou assimiladores de impactos.

Segundo Veiga (2005), para os economistas ecológicos (como Georgescu-Roegen e Daly) a crítica às sustentabilidades fraca (inovações) e forte (compensação) está no fato de os recursos naturais e capitais serem geralmente complementares e não substitutos; por isso, pensar que eles possam ser substituíveis é contrariar as duas leis da termodinâmica. Assim, para Daly (1996), o desenvolvimento sustentável quer dizer desenvolvimento sem crescimento (físico).

Tratando da macroeconomia ambiental de escala ótima, Daly ressalta que a macroeconomia é um subsistema aberto do ecossistema e é totalmente dependente, tanto como fonte para insumos de material/energia de baixa entropia e quanto como meio para a produção de material/energia de alta entropia. As trocas físicas que atravessam a fronteira entre o sistema ecológico total e o subsistema econômico constituem o assunto da macroeconomia ambiental.

Como afirma Daly (1996), a escala ótima, como justiça distributiva, pleno emprego ou estabilidade de nível de preço, é uma meta macroeconômica. A solução tradicional para tudo 
isto tem sido o crescimento da produção. Desse modo, portanto, colocam-se os objetivos da macroeconomia convencional em conflito com o conceito de escala ótima.

As questões de distribuição, de escala e de alocação são econômicas quando envolvem custos e benefícios. Mas as dimensões em que os custos e benefícios são definidos são diferentes nos três casos. Os preços alocativos nem sempre são relevantes para estimar os custos e benefícios de expansão de escala.

A distribuição e a escala envolvem relações com pobreza, o futuro e outras espécies que são fundamentalmente sociais na natureza, mais que individuais. Os preços que medem os custos de oportunidades de realocação não estão relacionados às medidas dos custos de oportunidades de redistribuição ou de uma mudança na escala.

Entretanto, em regra geral, não se tenta internalizar os custos externos de injustiça distributiva dentro de preços de mercado, pois isto traria indesejáveis efeitos sobre a distribuição de renda. Os economistas na atualidade mantêm alocação e distribuição muito separadas, e argumentam que preços servem apenas para eficiência, enquanto para atender a justiça há políticas separadas de transferências de riquezas através de programas sociais.

Para Daly (1996), nossas ações de inserções de retornos no ecossistema aumentaram em escala, e a induzida mudança qualitativa no ecossistema deve também aumentar, por duas razões: pela primeira lei da termodinâmica (a conservação do material/energético), ou seja, a simples ausência ou adição de um material/energético tem um efeito; a segunda razão é a segunda lei da termodinâmica, que garante que o material/energético de origem é qualitativamente diferente do material/energético inserido: a matéria-prima de baixa entropia sai e voltam resíduos de alta entropia.

Assim, a questão de assumir a não a escassez dos recursos ambientais e suas funções leva a uma economia de opressão, trazendo incerteza e, como retorno, surpresas de um ecossistema estressado por estar suportando uma economia tão grande.

Portanto, a sustentabilidade ecológica da produção não é garantida pelas forças de mercado, sendo que o mercado não pode por si só registrar os custos de seu próprio aumento relativo de escala para o ecossistema. Pois, os preços de mercado medem a escassez relativa de recursos individuais, não medem a escassez absoluta dos recursos em geral, de um meio ambiente de baixa entropia.

Com isso, Veiga (2005) destaca o movimento internacional liderado pela Comissão para o Desenvolvimento Sustentável (CSD) das Nações Unidas, cujo objetivo é construir indicadores, ou seja, mensurar a sustentabilidade. Mas é na produção do espaço que é possível compreender os desafios e os conflitos latentes na busca pela sustentabilidade ambiental. 


\section{Problemática ambiental urbana}

Com a produção capitalista, as mudanças socioespaciais que permeiam a rede urbana são reguladas pela lógica da acumulação de capital, e o resultado desse processo numa sociedade capitalista é o desenvolvimento desigual e injustiças sociais que são distribuídas tanto espacialmente quanto demograficamente.

O espaço é uma construção social em todas as suas dimensões. E isso significa que o é considerado como acidental, na produção do meio ambiente construído ou espaços de assentamento, devendo se tornar um objeto dirigido do pensamento social. Assim, a transformação da sociedade deve ser feita através de uma criação consciente de novas relações socioespaciais que vinculem as transformações no espaço e na vida da comunidade (GOTTDIENER, 2010; HARVEY, 2005).

Para identificar a natureza e o significado de uma rede urbana, para Corrêa (2006) a divisão territorial do trabalho; a relação com os ciclos de exploração; relações com a forma espacial; e o caráter mutável da rede urbana são pontos pertinentes, que não se excluem mutuamente.

Sendo que a rede urbana é o conjunto de centros urbanos que participam da criação, apropriação e circulação do valor excedente (juros, renda e lucros). A divisão territorial do trabalho cria uma hierarquia entre lugares e, segundo a sua distribuição espacial, redefine a capacidade de agir de pessoas, firmas e instituições. A divisão do trabalho supõe a existência de conflitos (SANTOS, 2009a).

A divisão social do trabalho é frequentemente considerada como a repartição do trabalho vivo. Essa distribuição vista através da localização dos seus diversos elementos, é chamada de divisão territorial do trabalho. Essas duas formas de considerar a divisão do trabalho são complementares e interdependentes.

Esse enfoque, todavia, não é suficiente, se não levarmos em conta que, além da divisão do trabalho vivo, há uma divisão territorial do trabalho morto. A ação humana tanto depende do trabalho vivo como do trabalho morto. O trabalho morto, na forma de meio ambiente construído, tem um papel fundamental na repartição do trabalho vivo (SANTOS, 2009a).

O meio ambiente construído constitui um patrimônio que não se pode deixar de levar em conta, já que tem um papel na localização dos eventos atuais. Desse modo, o meio ambiente construído se contrapõe aos dados puramente sociais da divisão do trabalho. Esses conjuntos de formas ali estão à espera, prontos para eventualmente exercer funções, ainda que limitadas por sua própria estrutura. 
O trabalho já feito se impõe sobre o trabalho a fazer. A atual repartição territorial do trabalho repousa sobre as divisões territoriais do trabalho anteriores. E a divisão social do trabalho não pode ser explicada sem a explicação da divisão territorial do trabalho, que depende, ela própria, das formas geográficas herdadas (SANTOS, 2009a).

A rede urbana dos países subdesenvolvidos constitui-se, em grande parte, na extensão de uma ampla rede com sede externa localizada nos países centrais. Neste sentido, a própria rede urbana é, através da função de intermediação, parte da divisão internacional do trabalho (CORRÊA, 2006).

Assim, a ideologia do desenvolvimento, que tanto foi apreciada nos anos 50, e, sobretudo, a ideologia do crescimento reinante desde fins dos anos 60, ajudam a criar a chamada metrópole corporativa, que direciona suas ações para deseconomias urbanas, deixando de atender a produção de serviços sociais e de bem-estar coletivo (SANTOS, 2009b).

Desse modo, o processo de urbanização corporativa se impõe à vida urbana como um todo, como processo contraditório que se opõe a parcelas da cidade, frações da população, formas concretas de produção, modos de vida, comportamentos.

Nos conflitos entre capital e trabalho para a apropriação de recursos e riquezas naturais, as alternativas de habitação, que incluem infraestrutura e serviços urbanos, demandadas pela maior parte da população, não são encontradas nem no mercado e nem nas políticas públicas.

Para Maricato (2007), as áreas ambientalmente frágeis em aglomerações urbanas ou industriais, que, por essa condição, merecem legislação específica e não interessam ao mercado legal, são as que passam a ser utilizadas como moradia de grande parte da população. Como principais consequências ocorrem à poluição dos recursos hídricos e dos mananciais, banalização de mortes por desmoronamentos, enchentes, epidemias etc.

Uma permanente tensão se estabelece entre a condição legal e a condição ilegal e o que elas representam para as instituições encarregadas de controle da ocupação do solo, financiamento habitacional e preservação ambiental, entre outras (MARICATO, 2007).

O "desenvolvimento sustentável" e o "meio ambiente" passam a constar em todos os documentos oficiais e oficiosos. A propriedade da terra, dos meios de produção, das riquezas "naturais" ou produzidas, do mundo do trabalho, bem como a concentração de terras e de riqueza, a pobreza, a necessidade de moradia adequada, de saneamento ambiental, de limpeza e iluminação pública, parecem desaparecer e deixam de ser analisadas no espaço geográfico (RODRIGUES, 2011, p.222). 
O impacto ambiental da acumulação capitalista gerado pelas frações de capital é identificado por Lefebvre (1999) como uma crítica ao capitalismo, uma vez que a destruição da natureza que tal sistema engendra através da industrialização ameaça romper os processos ecologicamente regeneradores, responsáveis pela sustentação da vida na terra.

As rupturas de causas diversas desencadeiam, portanto, processos de mudanças ecológicas e sociais combinadas, ou seja, impactos ambientais de natureza estrutural, produtores de novas mudanças que afetam de forma diferenciada e não planejada as estruturas de classes sociais (COELHO, 2004, p.37).

Mas, associar a noção de "sustentabilidade" à ideia de que existe uma forma social durável de apropriação e de uso do meio ambiente, dada pela própria natureza das formações biofísicas, por exemplo, significa ignorar a diversidade de formas sociais de duração dos elementos da base material do desenvolvimento (ACSELRAD, 2001).

Como convém a um país onde as leis são aplicadas de acordo com as circunstâncias, o chamado Plano Diretor está desvinculado da gestão urbana. Discurso pleno de boas intenções, mas distante da prática. (...) A habitação social, o transporte público, o saneamento e a drenagem não tem o status de temas importantes (ou centrais, como deveria ser) para tal urbanismo (MARICATO, 2007, p.64).

No entanto, a planificação urbana é voltada para os aspectos da cidade cujo tratamento agrava os problemas, em vez de resolvê-los. Esta é a planificação preocupada com aspectos singulares e não com a problemática global, planificação mais voltada para o chamado crescimento econômico, quando o que se necessita é de uma planificação sociopolítica que esteja de um lado preocupada com a distribuição dos recursos sociais e, de outro, consagre os instrumentos políticos de controle social, capazes de assegurar a cidadania plena (SANTOS, 2009b).

É necessário entender que a crise ambiental decorre do sucesso do modo de produção que provoca, contraditoriamente, problemas sociais e ambientais. E, assim, compreender o processo de produção de mercadorias e desvendar causas e agentes da poluição do ar, do solo, das águas, bem como dos desmatamentos e da perda das diversidades biológicas e sociais, determina que a crise não seja do modo de produção, mas sim, provocada por ele. 


\section{Uma breve evolução do espaço no território da Bacia do Itajaí}

A Bacia do Rio Itajaí é a maior bacia da vertente atlântica do Estado de Santa Catarina, com uma área de $15.500 \mathrm{~km} 2$, correspondendo a $16,15 \%$ do território catarinense. A área da bacia abarca 47 municípios e possui em torno de um milhão de habitantes, dos quais $76 \%$ concentram-se nos centros urbanos.

As primeiras áreas de ocupação no processo de colonização foram na foz do rio Itajaí, seguindo na região do Médio Vale por volta de 1850. A colonização do Alto Vale do rio Itajaí ocorreu em torno de trinta anos depois, pela constituição de pequenas propriedades, algumas vezes incentivadas por projetos de colonização (JOHNSSON; LOPES, 2003).

A ocupação e a formação territorial da Bacia do Itajaí tiveram início a partir de Itajaí, no Baixo Vale, mas foi estruturada a partir da Colônia Blumenau, no Médio Vale. A ocupação do Alto Vale é mais recente e deu-se a partir do Médio Vale. Blumenau e Brusque são os pontos a partir dos quais os Rios Itajaí-açu e Itajaí Mirim, descendo o Planalto, tornam-se navegáveis, escoando o comércio da sua hinterland para o Porto de Itajaí (FAAVI, 2010).

Os pequenos núcleos, que se desenvolveram a montante desses dois centros, atenderam aos habitantes de seus vales, mas convergiram para a realização de suas trocas vitais em Blumenau e em Brusque, as quais concentraram seus interesses econômicos e, desta forma, desenvolveram-se como centros regionais.

Na década de 1860, a Colônia de Blumenau já começa a se tornar um centro econômico de alguma importância na região, a ponto de atrair migrantes brasileiros. Em 1868 o governo enviou à colônia uma comissão de engenheiros e agrônomos para facilitar a instalação dos colonos em seus lotes. (...) $\mathrm{O}$ estabelecimento de linhas comerciais era justificável economicamente a partir de certo volume mínimo de produtos a serem transacionados (SINGER, 1977).

As enchentes no Vale do Rio Itajaí constituem um dos maiores problemas da bacia e remontam ao processo de assentamento dos primeiros núcleos humanos na região, em meados do século XIX. Tal sistema resulta das condições naturais da bacia hidrográfica, mas é acentuado por uma contínua sobrecarga da capacidade assimilativa e regenerativa do ambiente natural exercida pelo processo de produção do espaço estabelecido pela colonização estrangeira (THEIS et al., 2000).

Com o início do processo de industrialização, houve a expansão da rede de transporte para articular os mercados urbanos e rurais e o sistema comercial (posterior aos "vendistas") 
que, para distribuir os produtos industriais, adquiriu autonomia, deixando de lado a atividade agrícola e se dedicando ao caráter mais capitalista.

Conforme Lago (1999), nos espaços rurais e urbanos catarinenses a orientação geral de ocupação, com fortes motivações de uso da terra como recurso agronômico e extrativista vegetal, segue uma tendência histórica em que as relações homem/terra se intensificam nos espaços rurais, mas se refletem de forma contundente em restritos ambientes urbanos, onde se concentram os efeitos da construção antrópica.

A rede urbana do Vale do Itajaí estruturou-se no modelo hierárquico tradicional. No entanto, uma nova hierarquia urbana está se formando, com base na globalização da economia, que renova também a economia urbana. As melhorias nos sistemas de transporte e de comunicação possibilitam a descentralização industrial, o que altera o esquema hierárquico tradicional das redes urbanas, intensificando as trocas entre os diversos níveis urbanos e regionais.

Na década de noventa a desconcentração espacial das atividades econômicas se expressou no deslocamento de capitais e mão-de-obra qualificada para centros intermediários. As enchentes de 1983 e 1984 marcam esta mudança, que já se fazia sentir no elevado custo da terra, na falta de áreas planas propícias à urbanização e na elevação do custo da mão de obra.

A análise das taxas de crescimento dos municípios do Vale do Itajaí indica um crescimento mais acelerado no Baixo Vale do Itajaí. O Alto Vale apresenta a menor taxa média de crescimento. Já no Médio Vale, os municípios de Indaial, Brusque e Gaspar cresceram mais aceleradamente do que Blumenau.

No Baixo Vale as cidades que cresceram também são periféricas ao centro regional (Itajaí): Balneário Camboriú, Camboriú, Itapema e Navegantes. No Alto Vale o fenômeno ainda não ocorre. A incidência de municípios com taxa de crescimento total negativa é pequena, em geral, e levemente superior no Alto Vale. No entanto, com as taxas de crescimento rural a situação é diferente, pois $69 \%$ dos municípios estão perdendo população rural.

Por último, em relação à emancipação político-administrativa no Vale do Itajaí, podese dizer que, na medida em que as comunidades instaladas no Vale do Itajaí se desenvolveram, as antigas colônias se transformaram em cidades e distritos.

A seguir apresenta-se um estudo de indicadores socioeconômicos e ambientais dos 47 municípios da bacia do Itajaí. O exercício obteve resultados da análise dos componentes principais de variáveis municipais que pode ser utilizada como monitoramento, e estudos 
sobre as atividades econômicas predominantes e indicadores sociais, econômicos e ambientais.

\section{Metodologia}

Com base em estudos executados, utilizando os softwares de versão free do SPSS 16.0 e Philcarto, sobre análise descritiva e de inferência estatística (Bussab, 2003 e Kageyama, 2010), foram elaboradas as análises referentes aos dados de 47 municípios pertencentes à Bacia Hidrográfica do Itajaí. Os dados foram obtidos do Instituto Brasileiro de Geografia e Estatística (IBGE/ Sidra e IBGE/ Perfil dos Municípios) e do cadastro de usuários de água da Secretaria de Estado de Desenvolvimento Econômico e Sustentável de Santa Catarina (SDS/ Sirhesc), e foram construídos variáveis ou indicadores municipais que refletissem características do uso da água na Bacia do Itajaí (GOULART JUNIOR, 2011, 2013).

O índice de gestão dos recursos hídricos (Igrh), que mede a qualidade na adequação entre instituições municipais, condições do meio ambiente e ações de gestão dos recursos hídricos, foi construído a partir dos Suplementos Especiais sobre Meio Ambiente, no canal Perfil dos Municípios Brasileiros do site do IBGE. Os dados dos Suplementos Especiais sobre Meio Ambiente continham quatro tópicos principais, dos quais foram considerados apenas os itens referentes aos 47 municípios da Bacia do Itajaí, sobre: articulação institucional de meio ambiente; recursos financeiros para o meio ambiente; legislação ambiental; meio ambiente e condições de vida humana; recursos naturais (ar, água e solo) afetados; e ações de gestão dos recursos hídricos.

As variáveis consideradas foram referentes aos usos de água no meio rural da Bacia do Itajaí: IRD (relação da demanda hídrica do usuário irrigação com a total); CRD (relação da demanda hídrica do usuário pecuária com a total); CABSEST (cabeças de suínos por estabelecimento de criação); RPOP (população rural dos municípios da bacia do Itajaí); GINI (índice de concentração de renda municipal); YPC (renda per capita municipal); AREEST (área de estabelecimentos agrícolas do total municipal, que variam entre o ponto mínimo e máximo de 2,39 e 122, 16 hectares); e IGRH (índice de gestão dos recursos hídricos).

\section{Análise descritiva}

A análise descritiva foi elaborada considerando-se 16 variáveis utilizadas como indicadores socioeconômicos e ambientais para os municípios da Bacia do Itajaí, conforme a tabela 1 . 
Tabela 1 - Dados descritivos dos segmentos de usuários de água dos municípios da Bacia do Itajaí - SC

\begin{tabular}{|c|c|c|c|c|c|c|c|}
\hline & $\begin{array}{l}\text { Statistic N } \\
\text { Valid }\end{array}$ & Missing & Mean & Median & Std. Deviation & Min & Max \\
\hline $\begin{array}{l}\text { Ird - relação da demanda hídrica do usuário irrigação com a } \\
\text { total }\end{array}$ & 47 & 0 &, 42528 &, 24420 & ,409067 &, 000 & 1,000 \\
\hline $\begin{array}{l}\text { Ind - relação da demanda hídrica do usuário indústria com a } \\
\text { total }\end{array}$ & 47 & 0 &, 14389 & ,00643 &, 246790 & , 000 &, 865 \\
\hline $\begin{array}{l}\text { Crd - relação da dem. hídrica do usuário criação animal } \\
\text { com a total }\end{array}$ & 47 & 0 & , 19612 & ,00725 &, 327521 & ,000 & 1,000 \\
\hline Upop - população urbana dos municípios da bacia do Itajaí & 47 & 0 &, 53664 &, 52184 & 263574 & ,113 & ,963 \\
\hline Rpop - população rural dos municípios da bacia do Itajaí & 47 & 0 & ,46336 & ,47816 & 263574 & ,037 & 887 \\
\hline Gini - índice de concentração de renda municipal & 47 & 0 & ,48574 & ,47000 &, 050465 &, 390 & 620 \\
\hline Idh - índice de desenvolvimento humano municipal & 47 & 0 & ,72314 & ,72314 &, 061381 & ,613 & 829 \\
\hline Ypc - renda per capta municipal & 47 & 0 & 282,6657 & 267,3200 & 73,27704 & 157,00 & 507,63 \\
\hline Recpop - receita municipal per capta & 47 & 0 & 612,0019 & 547,2141 & 175,70918 & 393,85 & 1135,37 \\
\hline Despop - despesa municipal per capta & 47 & 0 & 529,0856 & 474,5740 & 170,30676 & 310,66 & 997,49 \\
\hline $\begin{array}{l}\text { Alavarm - relação da área de lavoura na área total } \\
\text { municipal }\end{array}$ & 47 & 0 & ,37059 &, 12393 &, 733574 &, 007 & 4,775 \\
\hline $\begin{array}{l}\text { Areest - área de estabelecimentos agrícolas do total } \\
\text { municipal }\end{array}$ & 47 & 0 & 16,75281 & 6,22849 & 29,798023 & 2,393 & 122,161 \\
\hline $\begin{array}{l}\text { VAest - valor adicionado municipal por estabelecimentos } \\
\text { industriais }\end{array}$ & 47 & 0 & 335,8151 & 292,0125 & 229,23334 & 88,15 & 1010,25 \\
\hline $\begin{array}{l}\text { Cabbest - cabeças de bovinos por estabelecimentos de } \\
\text { criação }\end{array}$ & 47 & 0 & 19,467 & 16,276 & 12,6932 & 8,3 & 80,1 \\
\hline Cabsest - cabeças de suínos por estabelecimentos de criação & 47 & 0 & 32,748 & 17,333 & 64,6856 & 2,8 & 441,6 \\
\hline IGRH - índice de gestão dos recursos hídricos & 47 & 0 & ,43830 & ,44000 & ,088914 &, 210 & ,620 \\
\hline
\end{tabular}

Fonte: Autor (SPSS 16.0)

Entre as variáveis utilizadas como indicadores socioeconômicos e ambientais, para bacias hidrográficas, que foram analisadas, estão: a relação da demanda hídrica do usuário irrigação com a total (Ird), a relação da demanda hídrica do usuário indústria com a demanda hídrica total (Ind), a relação da demanda hídrica de usuário criação animal com a demanda hídrica total (Crd), a relação da área de lavoura na área total municipal (Alavarm), a área de estabelecimentos agrícolas do total municipal (Areest) e o índice de gestão dos recursos hídricos (Irgh).

\section{Análise das correlações}

Entre as variáveis o índice de gestão de recursos hídricos e a relação da demanda hídrica do usuário irrigação com a total (Ird) foram as variáveis escolhidas para análise de suas principais correlações (mais significativas) com as outras variáveis.

O índice de gestão dos recursos hídricos (Igrh), que mede a qualidade na adequação das instituições municipais, as condições do meio ambiente e as ações de gestão dos recursos hídricos, apresentou correlação negativa com as variáveis de área de estabelecimentos agrícolas do total municipal (Areest), relação da área de lavoura na área total municipal (Alavarm) e cabeças de suínos por estabelecimentos de criação (Cabsest). 
Revista Catarinense de Economia - RCE

APEC - Associação dos Pesquisadores em Economia Catarinense

1을 Semestre de 2017 - www.apec.pro.br/rce

\subsection{Análise de clusters}

Com a base cartográfica, foram elaborados cinco mapas caracterizando os municípios em cinco grupos diferentes, conforme o índice de gestão de recursos hídricos, o valor adicionado industrial e a demanda hídrica, demanda de água da criação de suínos por estabelecimentos, demanda de água para irrigação por estabelecimentos agrícolas, e, ainda, o índice de gestão de recursos hídricos por área dos estabelecimentos agrícolas.

A relação de indicadores socioeconômicos e ambientais na área municipal apresentada nos mapas simplifica a análise e facilita discussões e ações necessárias à bacia hidrográfica em questão.

Nesta comparação (figura 1) entre a variável do IGRH e a população total municipal (Popt), observa-se que os municípios mais populosos apresentam certo equilíbrio com os demais municípios da Bacia do Itajaí, com relação ao índice de gestão dos recursos hídricos, pois 25 municípios que representam 53,19\% do total contam com um IGRH entre 0,40 e 0,48, independentemente do número de habitantes.

Figura 1 - Bacia do Itajaí - índice de gestão de recursos hídricos pela população municipal total

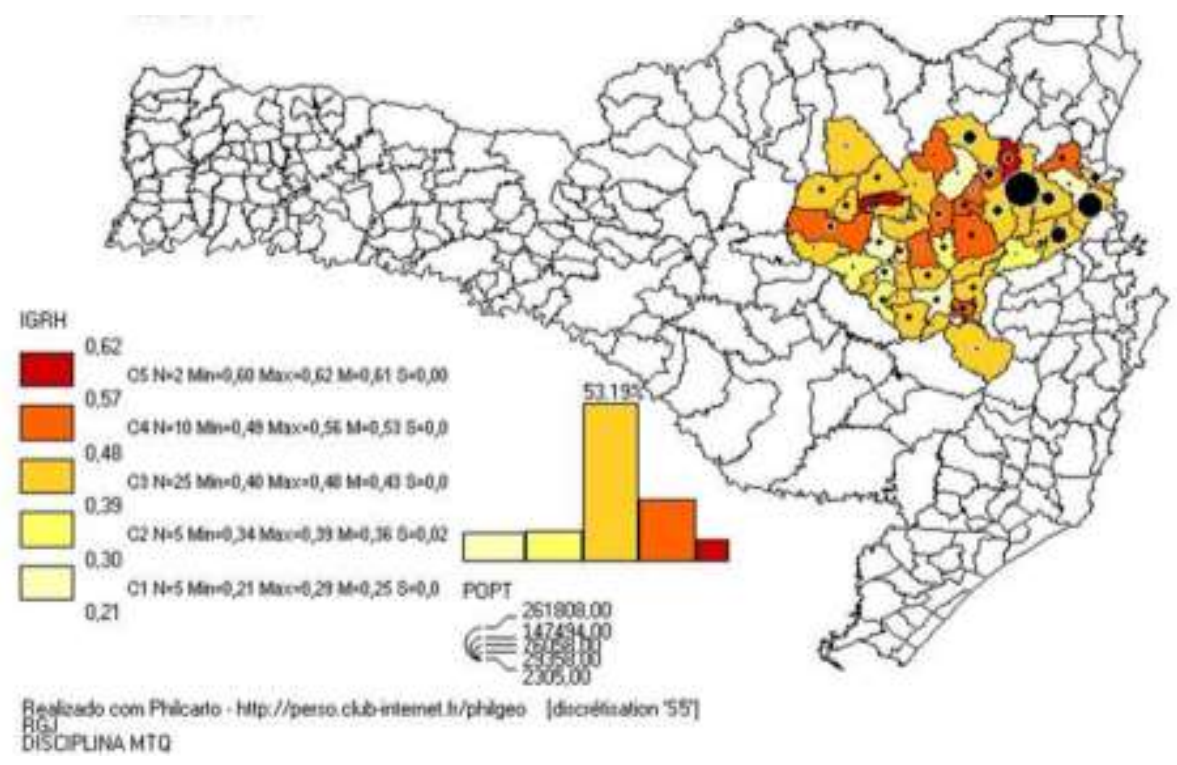

Fonte: Autor (SPPS 16.0)

Conforme a figura 2, que relaciona as variáveis da demanda hídrica da Indústria (Ind) com o Valor Adicionado municipal por estabelecimentos industriais (VAest), a demanda hídrica da indústria determina grande parte do Valor Adicionado nos municípios onde existe a presença dos subsetores industriais de têxteis e vestuário, metalmecânico, frigoríficos e 
alimentos, presentes nos municípios da faixa C5 com as maiores demanda hídricas (Ind) entre 0,55 e 0,86 .

Figura 2 - Bacia do Itajaí - valor adicionado industrial e a demanda hídrica da indústria

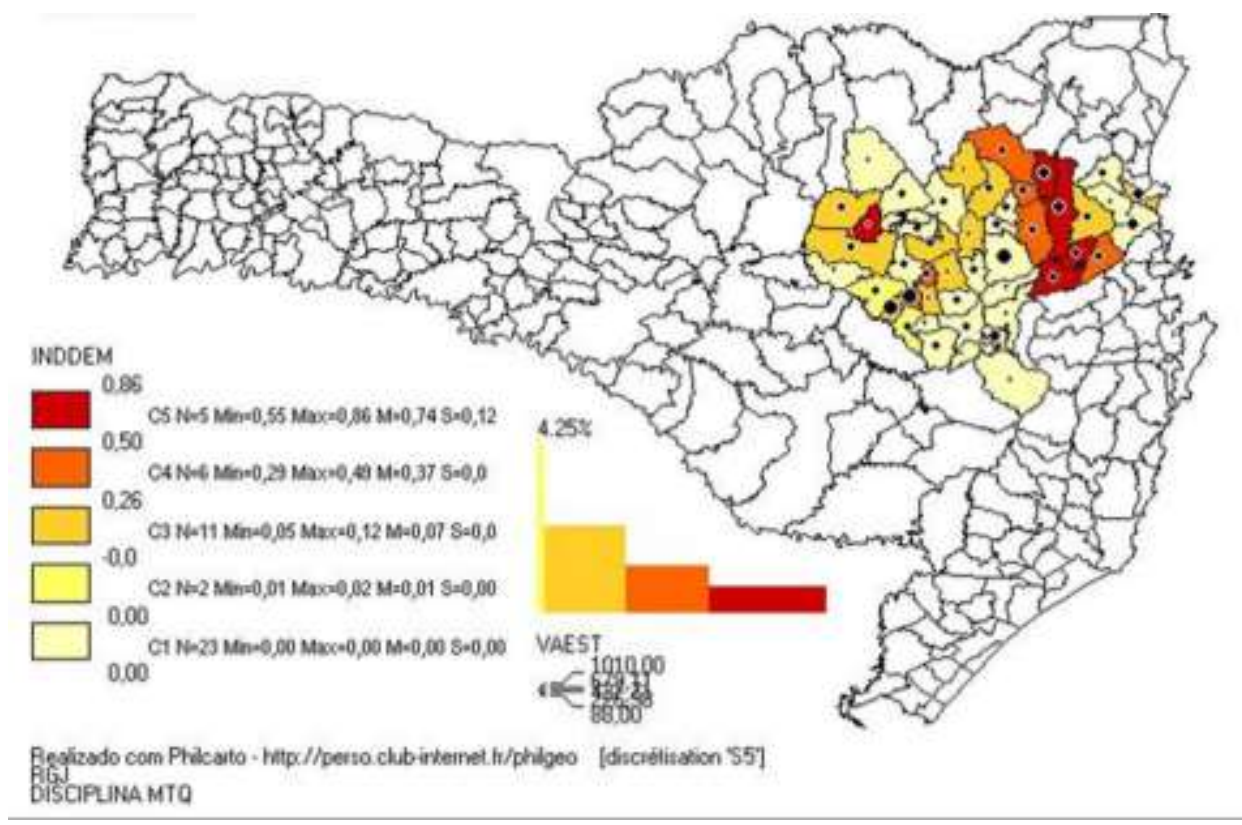

Fonte: Autor (SPPS 16.0)

Na comparação (figura 3) entre a demanda hídrica de criação animal (Crd) e a variável de cabeças de suínos por estabelecimentos de criação (Cabsest), pode-se observar que as maiores demandas hídricas estão em propriedades médias dos oito municípios com média de 0,85, e significância de 0,10 , ou seja, possibilidade de $10 \%$ de erro amostral.

Já as grandes propriedades (com maior número de cabeças) estão na faixa de demanda hídrica de C3, com significância de 0,0 e média de 0,11, ou seja, sugerindo uma melhor eficiência no uso da água para a atividade de criação animal. 
Figura 3 - Bacia do Itajaí - demanda hídrica da criação animal e estabelecimentos criadores de suínos

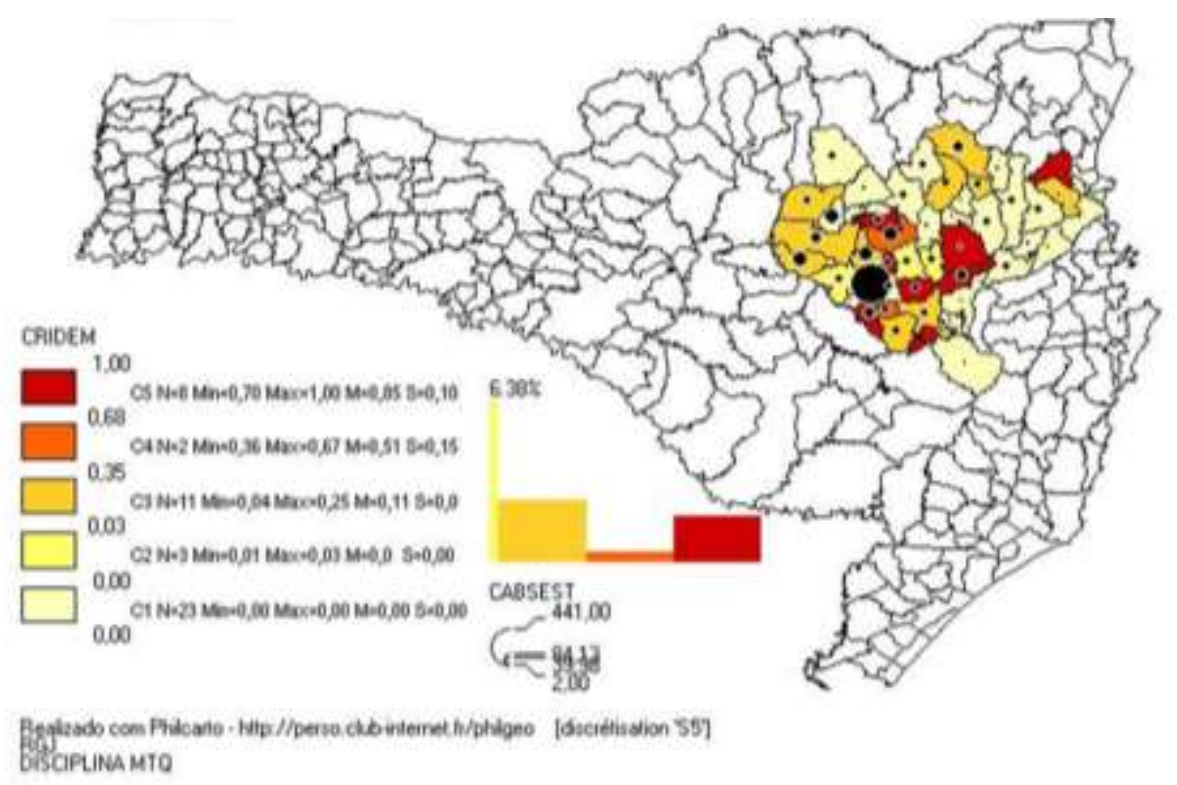

Fonte: Autor (SPPS 16.0)

$\mathrm{Na}$ figura 4, pode-se observar que os grandes produtores agrícolas, principalmente com lavoura temporária de arroz, apresentam uma demanda hídrica da irrigação nas faixas C3 e C4, com médias de 0,35 e 0,87 , sendo que apenas a C4 é significativa, com erro amostral bem abaixo de $10 \%$.

Os demais municípios da faixa entre 0,68 e 1,00 da Ird podem ser caracterizados como pequenos produtores que cultivam o fumo, a cebola e a mandioca, além do arroz e, assim, representam no seu agregado a maior parte da demanda hídrica do segmento de irrigação (Ird) na Bacia do Itajaí. 
Figura 4 - Bacia do Itajaí - demanda hídrica da irrigação e a área de estabelecimentos agrícolas

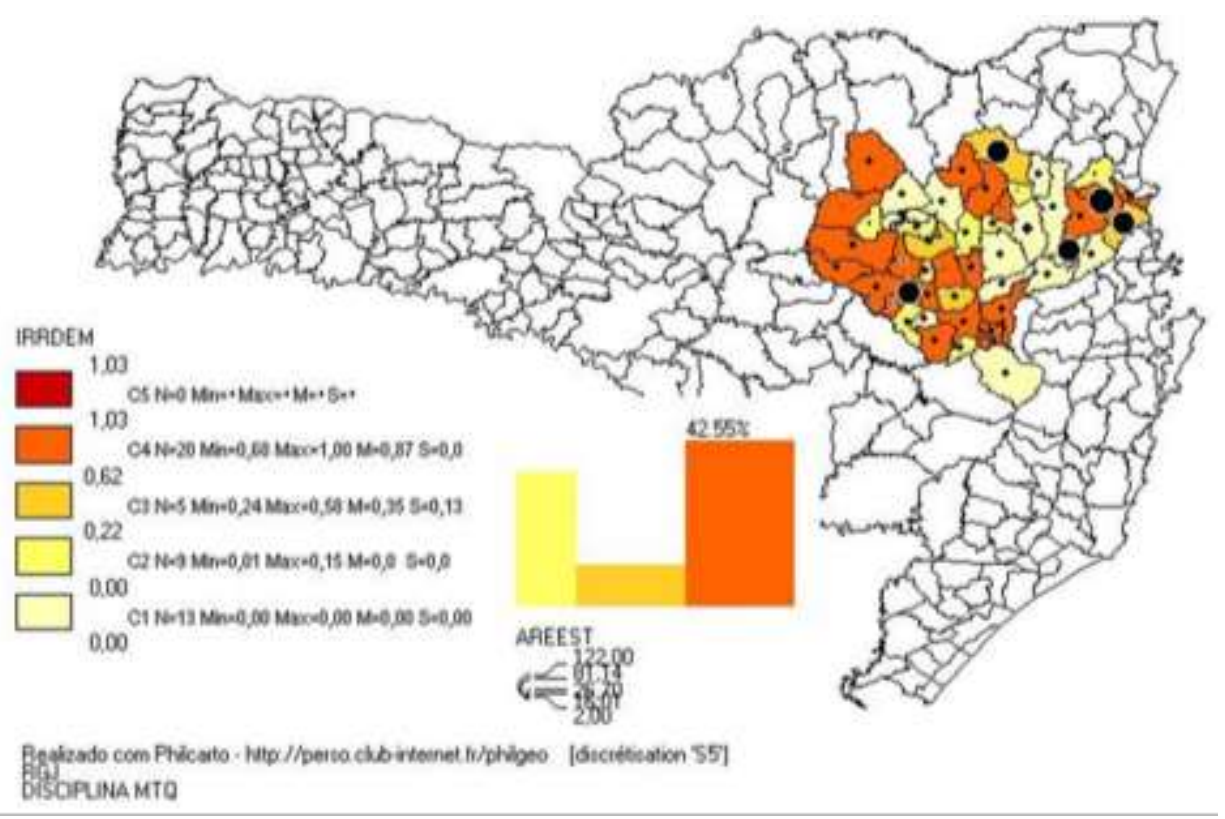

Fonte: Autor (SPPS 16.0)

Na comparação da variável Areest com o IGRH (figura 5), os municípios com grandes propriedades agrícolas e suas principais culturas, mormente lavouras temporárias, encontramse nas faixas C2 e C3, com IGRH entre 0,34 e 0,48, ou seja, sugerindo um IGRH de médio para baixo, referente aos valores observados nos municípios da Bacia do Itajaí.

Figura 5 - Bacia do Itajaí - índice de gestão de recursos hídricos e a área de estabelecimentos agrícolas

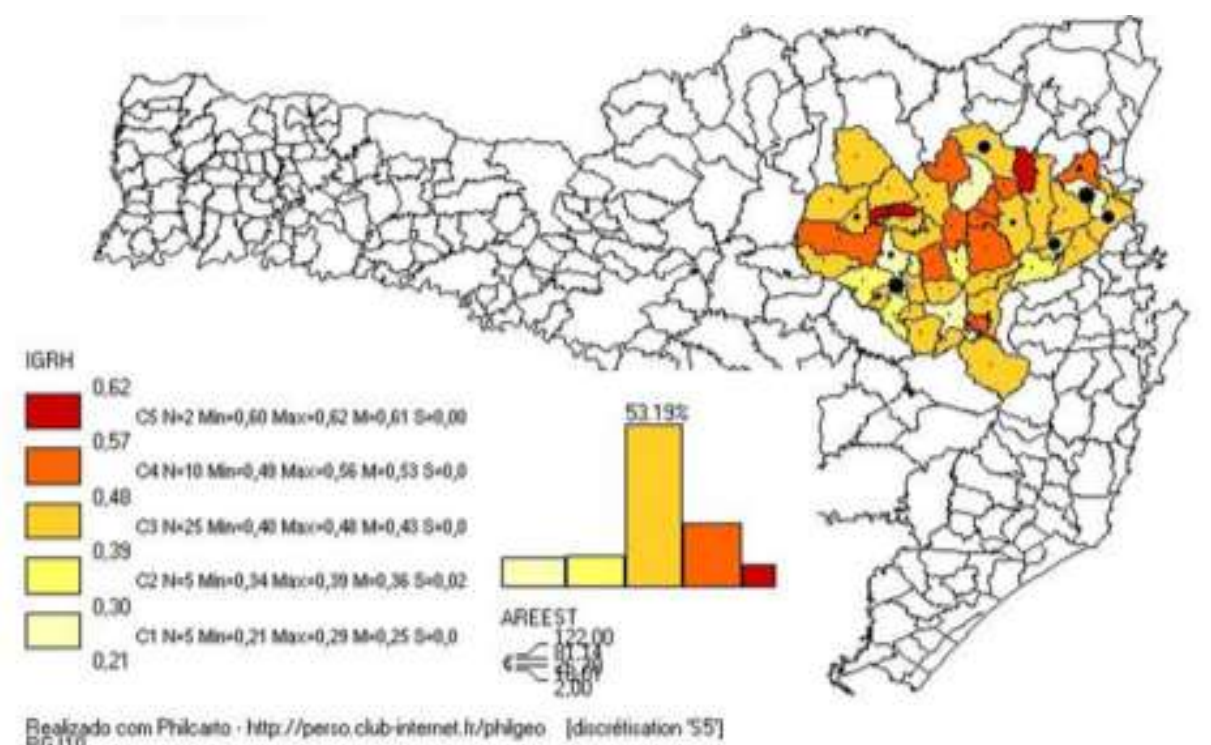

Fonte: Autor (SPPS 16.0) 


\subsubsection{Análise de variável binária "Areestbin"}

Ao considerar dois grupos de municípios com área de estabelecimentos agrícolas menores e maiores que 20 hectares (Areestbin), o resultado do Teste t demonstra que o índice de gestão dos recursos hídricos (Igrh) apresenta médias diferentes entre os dois grupos estudados, rejeitando-se a hipótese nula (Ho) devido ao pequeno erro de 1,2\%.

Assim, no grupo com área agrícola menor de 20 há, a média do IGRH foi de 0,45, apresentando melhor qualidade na gestão dos recursos hídricos; já no grupo com área agrícola maior de 20 há, a média do IGRH foi de 0,35, que, comparada com o outro grupo sugere apresentar uma gestão menos eficiente dos recursos hídricos.

No teste F, o índice de gestão dos recursos hídricos (Igrh), comparando os dois grupos de municípios, assume que as suas variâncias são iguais, ou seja, aceita-se a hipótese nula (Ho) com significância de 0,263, determinando erro acima de $26 \%$ caso assumisse a hipótese alternativa.

Assim, os grupos de municípios da amostra (com menos e mais de 20 ha) na variável IGRH não são afetados pela variável binária (Areestbin). Isto ocorre porque os seus desviospadrão não se alteram, ou seja, entre os dois grupos de municípios assume-se que a presença de grandes ou pequenas propriedades agrícolas não (pouco) pode afetar a variável do índice de gestão dos recursos hídricos (Igrh).

\subsection{Análise dos componentes principais}

Nesta análise a avaliação das diversas variáveis é feita considerando-se o padrão de agrupamento realizado a partir da distância euclidiana média. A importância relativa dos caracteres é avaliada pelo método dos componentes principais, em que as variáveis são identificadas a partir dos elementos dos autovetores associados aos menores autovalores da matriz de correlação entre os dados originais.

Utilizando o Método de Rotação Varimax (SPSS $®)$ ) obtiveram-se três componentes com mais de $65 \%$ de variância explicada. No Componente 1 as variáveis com maior correlação (RPOP com $+0,859$ e YPC com -0,865) estão influenciando este fator 1 com a determinação de que "municípios com grande população rural apresentam baixa renda", ou seja, municípios rurais com baixa renda. No Componente 2, as variáveis com maior correlação (AREEST com +0,754; CABSEST com +0,762; e IGRH com -0,794) estão influenciando este fator 2 com a determinação de que "municípios com grande agropecuária apresentam pior gestão dos recursos hídricos", ou seja, municípios agropecuários com baixo IGRH. Já no Componente 3, as variáveis com maior correlação (IRD com -0,755; CRD com 
+0,729; e GINI com +0,561) estão influenciando este fator 3 com a determinação de que "municípios com alta demanda hídrica para pecuária e com concentração de renda têm baixas demandas hídricas para agricultura", ou seja, municípios com pecuária e concentração de renda.

Tabela 2 - Componentes com mais de $65 \%$ de variância explicada das variáveis

\begin{tabular}{lccc}
\hline & \multicolumn{3}{c}{$\begin{array}{c}\text { (Rotated Component Matrix) } \\
\text { Component }\end{array}$} \\
\hline IRD & C1 & C2 & C3 \\
CRD & 0,358 & 0,032 & $\mathbf{- 0 , 7 5 5}$ \\
RPOP & 0,227 & 0,042 & $\mathbf{0 , 7 2 9}$ \\
GINI & $\mathbf{0 , 8 5 9}$ & $-0,100$ & 0,286 \\
YPC & 0,097 & $-0,019$ & 0,561 \\
AREEST & $\mathbf{0 , 8 6 5}$ & $-0,078$ & 0,096 \\
CABSEST & $-0,390$ & $\mathbf{0 , 7 5 4}$ & $-0,028$ \\
IGRH & 0,053 & $\mathbf{0 , 7 6 2}$ & 0,181 \\
& $-0,175$ & $\mathbf{- 0 , 7 9 4}$ & 0,201 \\
\hline
\end{tabular}

\subsection{Método de agrupamentos hierárquicos (Ward)}

Neste método consideram-se, para a formação inicial do grupo, aqueles dados que proporcionam a menor soma de quadrados do desvio. Admite-se que, em qualquer estágio, há perda de informações em virtude do agrupamento realizado, o qual pode ser quantificado pela razão entre a soma de quadrados dos desvios e a soma de quadrados total dos desvios.

Então, a soma de quadrados dos desvios dentro é calculada considerando-se apenas os acessos dentro do grupo, e a soma de quadrados dos desvios total é calculada levando-se em conta todos os indivíduos disponíveis para a análise de agrupamento. A análise é feita a partir das somas de quadrados dos desvios entre acessos ou, alternativamente, a partir do quadrado da distância euclidiana.

Assim, a partir das variáveis dos 47 municípios da Bacia do Itajaí, foram considerados, após análise do "dendograma", quatro "clusters" com fatores extraídos, e então foram construídos os Gráficos dos Scores (municipais) confrontando os três componentes principais, ou seja, $\mathrm{C} 1$ com $\mathrm{C} 2$, e $\mathrm{C} 2$ com $\mathrm{C} 3$.

Na figura 6, o Cluster 1 tem a maior parte composta por municípios rurais de baixa renda per capita que apresentam baixa participação agropecuária e IGRH equilibrado. Mas há municípios que apresentam grande participação agropecuária e pior IGRH. O Cluster 2 tem a 
maior parte composta, também, por municípios rurais de baixa renda per capita que apresentam baixa participação agropecuária e IGRH equilibrado; com exceção de ITU, AGR, PRN, PRG e LAU, com maior participação agropecuária e pior IGRH. O Cluster 3 tem a maior parte composta por municípios não rurais (urbanos) de alta renda per capita que apresentam baixa participação agropecuária e melhor IGRH; com exceção de RIS, GUA, ITA, ILH e IND, com grande participação agropecuária e pior IGRH. E o Cluster 4 é composto pelo município rural de TRO, de baixa renda per capita, que apresenta grande participação agropecuária e o pior IGRH.

Figura 6 - Scores entre componente 1 e componente 2

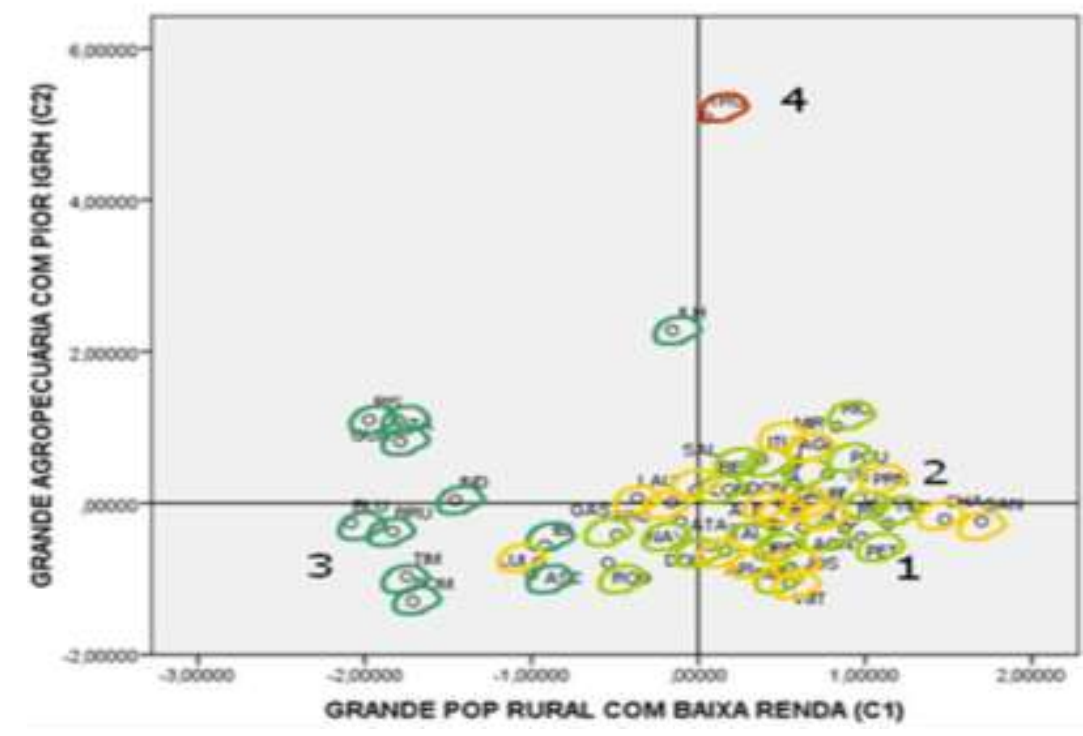

Fonte: Autor (SPPS 16.0)

Na figura 7, o Cluster 1 tem a maior parte composta por municípios com alta demanda hídrica agrícola e renda menos desigual, que apresentam um equilibrado IGRH. Mas há municípios que apresentam grande participação agropecuária e pior IGRH, como BEN, ITU, POU, MIR e GUA. O Cluster 2 tem a maior parte composta por municípios com alta demanda hídrica pecuária e renda mais desigual, que apresentam baixa participação agropecuária e melhor IGRH; com exceção de SAL, AGL, LAU, PRN e DON, com maior participação agropecuária e pior IGRH que os outros municípios do grupo. O Cluster 3 tem a maior parte composta por municípios com pouca demanda hídrica agrícola e pecuária (urbanos) e renda com pouca desigualdade, que apresentam baixa participação agropecuária e melhor IGRH; com exceção de RIS, GUA, ITA e ILH, com grande participação agropecuária e pior IGRH que os outros municípios do grupo. O Cluster 4 é composto pelo município de TRO, com alta 
demanda hídrica pecuária e renda muito desigual, que apresenta grande participação agropecuária e o pior IGRH.

Figura 7 - Scores entre componentes 2 e componentes 3

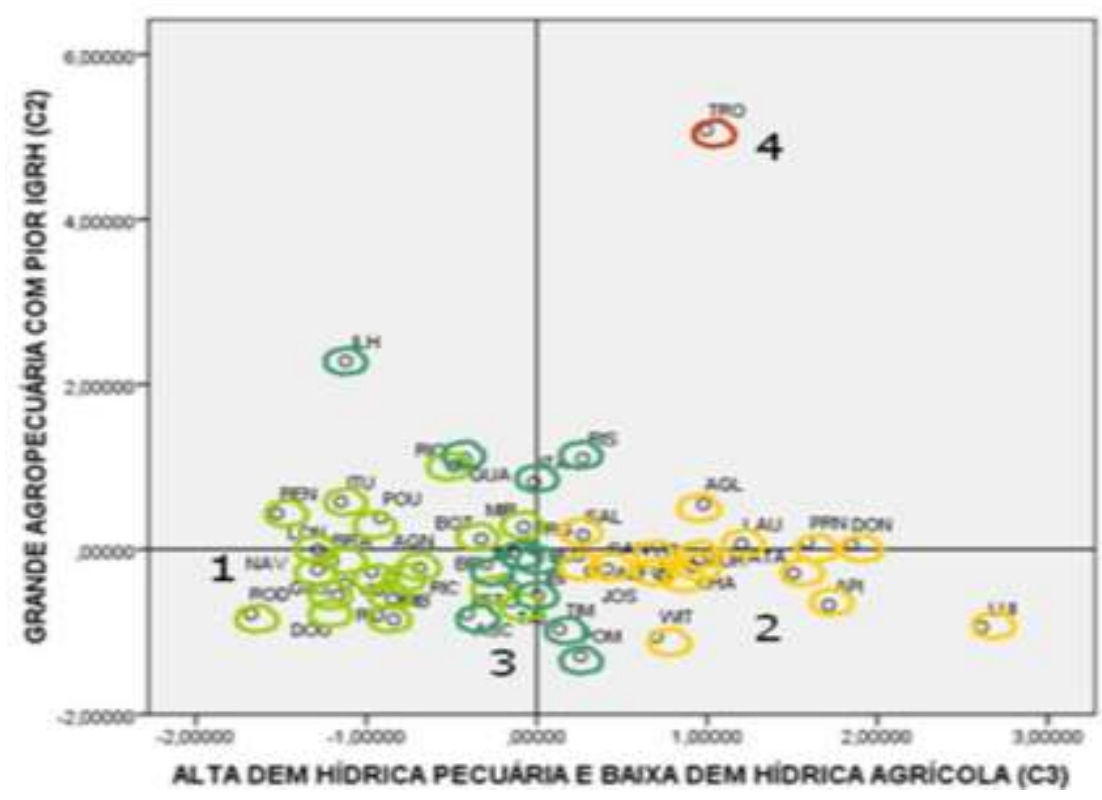

Fonte: Autor (SPPS 16.0)

Com isso, pode-se estudar, mesmo que parcialmente, a formação socioespacial, a configuração territorial e a heterogeneidade espacial encontradas no território da Bacia Hidrográfica do Itajaí, na região do Vale do Itajaí. Os municípios com predomínio das atividades pecuárias apresentaram um pior IGRH, indicando, talvez, a necessidade de melhor controle e participação municipal nas questões ambientais e ações ligadas aos recursos hídricos.

\section{Considerações finais}

O processo de crescimento econômico, considerando a problemática ambiental e da desigualdade social, deve ser analisado considerando-se alguns problemas que questionam o crescimento; enquanto a análise dos conceitos de desenvolvimento sustentável e de sustentabilidade confronta as visões da economia neoclássica e da economia ecológica, pois o crescimento econômico de bens materiais é insustentável na escala socioecológica.

No Brasil, a planificação está preocupada com aspectos singulares e não com a problemática global: é o planejamento para o crescimento econômico. O que se necessita é de uma planificação sociopolítica que minimize a problemática ambiental urbana. Pois a crise 
ambiental é inerente ao modo de produção capitalista, que intensifica os problemas sociais e ambientais. E, com isso, pode-se compreender o processo de produção de mercadorias e desvendar as causas e os agentes da poluição, dos desmatamentos, das perdas ecológicas e sociais.

O estudo da produção do espaço em determinado território, como o da bacia do Itajaí, pode identificar o processo da configuração territorial e da heterogeneidade espacial, acrescentando características socioambientais do recorte hidrográfico por meio de análise estatística de indicadores sociais, econômicos e ambientais.

Assim, esforços são necessários, exigindo mais estudos que subsidiem o planejamento e a tomada de decisões na gestão de recursos hídricos e em políticas setoriais e territoriais. E, por isso, a construção de indicadores pode contribuir na mensuração da sustentabilidade.

Nos estudos referentes aos dados de 47 municípios pertencentes à Bacia Hidrográfica do Itajaí, demonstra-se que os indicadores municipais sugeridos a partir de análise estatísticas multivariadas são importantes para a definição, em municípios estudados, de características socioeconômicas e ambientais que reflitam o uso da água na bacia hidrográfica.

\section{Referências}

ABRAMOVITZ, M. Thinking about growth: and other essays on economic growth and welfare, Cambridge: Cambridge University press, 1989.

ACSELRAD, H. (Org.) A duração das cidades: sustentabilidade e risco nas políticas urbanas. Rio de Janeiro: DP\&A, 2001.

ARRIGHI, G.. A ilusão do desenvolvimento. Petrópolis: Vozes, 1997.

ALTVATER, E. O preço da riqueza: pilhagem ambiental e a nova (des)ordem mundial. Tradução de Wolfgang Leo Maar. São Paulo: Editora UNESP, 1996.

BUSSAB, W.O.; MORETTIN, P.A. Estatística básica. $5^{\text {a }}$ edição. São Paulo: Saraiva, 2003.

COELHO, M.C.N. Impactos ambientais em áreas urbanas: teorias, conceitos e métodos de pesquisa. In: GUERRA, A.J.T.; CUNHA, S. B. da (Orgs.). Impactos ambientais urbanos no Brasil. 2.ed. Rio de Janeiro: Bertrand Brasil, 2004.

CORRÊA, R. L. Sobre agentes sociais, escala e produção do espaço: um texto para discussão. In: CARlOS, A. F. A.; SOUZA, M. L. de; SPOSITO, M. E. B. (Orgs.) A Produção do espaço urbano: agentes e processos, escalas e desafios. São Paulo: Contexto, 2011.

CORREAA, R. L. Estudos sobre a rede urbana. Rio de Janeiro: Bertrand Brasil, 2006.

DALY, H. E. Beyond growth: the economics of sustainable development. Boston: Beacon Press, 1996.

FAAVI - FUNDAÇÃO AGÊNCIA DE ÁGUA DO VALE DO ITAJAÍ. Plano de recursos hídricos da Bacia do Itajaí, Blumenau: Comitê do Itajaí / FAAVI, 2010. Disponível em: http://www.aguas.sc.gov.br/index.php?option=com_k2\&view=item\&layout=item\&id=190 $\underline{4 \& \text { Itemid=248\&jsmallfib=1 \&dir=JSROOT/DHRI/Planos+de+Bacias/Plano+da+Bacia }+\mathrm{Hi}}$ drografica+do+Rio+Itajai

GOTTDIENER, M. A produção social do espaço urbano. 2. ed. São Paulo: Ed. da USP, 2010.

GOULART JUNIOR, R. Crescimento (in)sustentável e o estudo de indicadores socioeconômicos municipais da Bacia Hidrográfica do Itajaí. In: V ENCONTRO DE ECONOMIA CATARINENSE, 2011, Florianópolis. Anais..., Florianópolis: APEC/UDESC, 2011. CD-ROM. 
GOULART JUNIOR, R. Produção do espaço no território da Bacia Hidrográfica do Itajaí e a análise de indicadores socioeconômicos e ambientais. In: VII ENCONTRO DE ECONOMIA CATARINENSE, 2013, Florianópolis. Anais..., Florianópolis: APEC/UFSC, 2013. CD-ROM.

HARVEY, D. A produção capitalista do espaço. São Paulo: Annablume, 2005.

JOHNSSON, R. M. F.; LOPES, P. D. (Orgs.). Projeto Marca d'Água: seguindo as mudanças na gestão das bacias hidrográficas do Brasil - Caderno 1 - retratos $3 \times 4$ das bacias pesquisadas. Brasília: FINATEC, 2003.

KAGEYAMA, A. Material da Disciplina HO-341 Métodos Quantitativos Aplicados à Economia. IE/Unicamp, 2010/1.

LAGO, P. F. Santa Catarina: dimensões e perspectivas. Florianópolis: Ed. da UFSC, 1978.

LEFEBVRE, H. A revolução urbana. Belo Horizonte: Ed. da UFMG, 1999.

LEFEBVRE, H. O direito à cidade. São Paulo: Centauro, 2001.

MARICATO, E. Globalização e política urbana na periferia do capitalismo. In: RIBEIRO, L. C. Q.; SANTOS Jr., O. A dos. (Orgs.) As metrópoles e a questão social brasileira. Rio de Janeiro: Ed. Revan, 2007.

RODRIGUES, A. M. A matriz discursiva sobre o "meio ambiente": produção do espaço urbano agentes, escalas, conflitos. In: CARLOS, A. F. A.; SOUZA, M. L. de; SPOSITO, M. E. B. (Orgs.). A produção do espaço urbano: agentes e processos, escalas e desafios. São Paulo: Contexto, 2011.

SACHS, I. Desenvolvimento includente, sustentável e sustentado. Rio de Janeiro: Garamond, 2008.

SANTOS, M. A natureza do espaço: técnica e tempo, razão e emoção. 4.ed. São Paulo: Editora da Universidade de São Paulo, 2009a.

SANTOS, M. A urbanização brasileira. 5.ed. São Paulo: Editora da Universidade de São Paulo, 2009b.

SEN, A. Desenvolvimento como liberdade. São Paulo: Companhia das Letras, 1999.

SINGER, P. Desenvolvimento econômico e evolução urbana. 2.ed. São Paulo: Companhia Editora Nacional, 1977.

THEIS, I. M. Processo de acumulação em Blumenau: uma interpretação crítica. In: THEIS, I.M; MATTEDI, M.; TOMIO, F. (Orgs). Nosso passado (in) comum: contribuições para o debate sobre a história e a historiografia em Blumenau. Blumenau: Ed. da Furb: Ed. Cultura em Movimento, 2000.

VEIGA, J. E. Desenvolvimento sustentável: o desafio do século XXI. Rio de Janeiro: Garamond, 2005. 